\title{
Empirical Analysis of a Generalized Darwinism Triggered Theory of Evolutionary Marketing Research
}

\author{
Ghada Gad \\ Canadian International College, Egypt \\ Wael Kortam \\ Cairo University, Egypt
}

\section{INTRODUCTION}

The main importance of this research lies at contribution to theory development in marketing research. as argued by the conceptual framework marketing need to improve its scientific credentials as an academic discipline to which the three main streams of this research will aim to make a significant improvement of marketing as a science; The dependent variable which is nomlinear marketing agenda is argued to improve the integration academic understanding of marketing phenomena insights and outlook, configuring and devising generalized Darwinism as an independent variable and evolutionary marketing research as an intervening variable should be expected to help in reflecting a new understanding of how the marketing research process can considerably boost the scientific status of marketing through full filling the above indicated nonlinear marketing agenda, and this research is also interested on the marketing practice level to help in bridging the gap between marketing theory and practice. The reconciliation essence of nonlinear marketing should create streams of marketing research that probably comply, revisit and blur marketing boundaries to create more advanced, yet down-to-earth marketing knowledge. Using the philosophy of generalized Darwinism and evolutionary marketing research are argued by this research to accomplish significantly high level of relevant and applicability leading to a more practice-theory of non-linear marketing.

\section{THEORETICAL BACKGROUND}

In the biological world, evolution occurs over time through the key Darwinian mechanisms of variation (of genotypes), selection (of the consequent phenotype) and replication or inheritance (of the underlying genotype), where the genotype is defined as the information inherited by an individual from its parents (i.e. genes), which has the potential to be transmitted to future generations. The phenotype, in contrast, is the developmental expression of the genotype in a particular environment, as manifest through the physical characteristics of the organism (Breslin, 2010).

The statue of Charles Darwin, neglecting the cove where the scientist ventured aground on Chatham, now san Cristobal, the foremost easterly of the Galapagos islands rouses the ways in which evolutionary theory can contribute to our understanding of social sciences in general and marketing theory in particular (Barnett, 1996 and Vollmer 2010). It appears barely possible that insight observation of finches, mocking birds and tortoises may change the way researchers think about the world, but in the 19th century it happened. The Galapagos, 700 miles from the mainland of Ecuador, contain Flora and Fama that contrast from those of the rest of the world and differ, but 
less, from island to island. Darwin was to secure the method by which this design came about. Evolution is a process with three stages or phases: - variation, selection, and replication. Changes happen, a few of these changes yield advantage, and such changes tend to be duplicated in subsequent generations. The additional outcome coming to in its implications that Darwin hesitate to distribute his ideas that designs of extra ordinary complexity and effectiveness can be accomplished without the help of one single superior experts of design. Designs can develop beyond the comprehension of any person (Chiou and Pan 2008 and Saad and Gill 2000). That understanding and the mechanics of variation, selection and replication are relevant to numerous issues other than the origin of species.

On the other side of the contention presented by this research, an emerging state-of-the-art, critical and innovative evolutionary viewpoint on present and modern marketing research thought could be formulated to lead to designing the marketing research process as a scientific transformation and change process as proposed by Kortam (2006). This proposed process is seen as concerned with looking at and positively dealing ill-informed marketing issues and analytical gaps in marketing theory and practice. Based on that vision, the marketing research process can be, arguably, conceptualized as comprising of three fundamental continuous phases.

the marketing research process can be arguably conceptualized as three main consecutive phases as per (Kortam, 2006);

First, an encoding of concept phase pointing to encode marketing problems and/ or opportunities into scientific terms in the form of marketing research questions/ hypotheses. The quintessence of this encoding stage through carrying out exploratory problem/ opportunity definition activities to formulate research hypotheses or questions. The most concern here should be on the comprehensive encoding of all the concepts constituting the specific and particular aspects of the problem/opportunity under research.

Second, An application of marketing research methods phase which looks for rigorously and verifiably implement the scientific process and adopt tools of marketing research. The most concern of this stage is to reach scientifically-grounded marketing solutions to solve encoded marketing problems or encoded opportunities seizing. The main concern of this stage is hung upon the strict and efficient systematic conduct of the conclusive marketing research activities of sampling design and plan, development of measurement scales, data collection and finally preparation and data analysis.

Third, A decoding to context phase, which basically includes translating scientific marketing solutions to defined problems and/ or opportunities in to actionable marketing decisions and policies. The conclusive marketing research activities of this stage are those of interpretation of analyzed and reporting these interpretations with a view toward expanding and advancing research recommendations and findings. The most concern of this phase is to come up with insightful, quick, far reaching, precise and creative interpretations of findings that are valuable within the context in which marketing organizations encountering such problems/opportunities work. As a wrap up, this configuration by (Kortam, 2006) contends that the value added of marketing research rests on a comprehensive encoding of marketing research inputs, a rigorous 
Gad, G., \& Kortaam, W. (2020) Empirical Analysis of a Generalized Darwinism Triggered Theory of Evolutionary Marketing Research. Archives of Business Research, 8(5). 274-297.

application of marketing research process and a reasonable, realistic and action-oriented interpretation and translation of marketing research outputs.

\section{ANTICIPATED CONTRIBUTIONS OF THE MODEL.}

It is expected that the following theory and policy implications would result from formulating the model as new contributions made by this research:-

1. Introducing a clear understanding of how generalized Darwinism can broaden and deepen marketing research concepts and principles to be philosophical enough through being evolutionary insightful and foresightfully.

2. Conceptualization of Darwinism based evolutionary marketing research as a devise theory to be highly philosophical adequate to achieve higher marketing ends like marketing research dualities of ideology/ methodology, truth/wisdom, gap between theory and practice and improving marketing as a science intellectually and empirically (intelligentsia /empiricism).

3. Visualization of a tangible achievement of higher marketing ends through optimization of non-linear marketing deliverables.

4. Opening new venues for examining advanced marketing research issues through real innovative and highly un-tested marketing research contexts such as marketing research panels and marketing research analytical techniques such as meta-analysis.

\section{LIMITATION OF THE MODEL}

There can be a limitation of each above contribution for making the generalization to make them safe:-

1. Contribution one is limited by the use of Generalized Darwinism as one conceptual interpretation of Darwinism and by Darwinism in its broad sense as one philosophical drive for advanced marketing research which might include relativity, argumentation and critic.

2. Contribution two is limited by using marketing research alone as one critical landmark of the marketing landscape. Further reference could be made to potential evolutionary strategic marketing, buyer behavior and marketing management.

3. Contribution three is limited by the argument that non-linear contributions represent one of at least three more high areas of marketing agenda including polarized and explosive marketing wisdom.

4. contribution four is limited by the use of panels while there is also could be room for systematic sampling and quota sampling as time sensitive and population focused context of marketing research. Also, logistic regression, cluster analysis and path analysis could be useful and valid replacements of meta-analysis for the same non-linear or other higher marketing ends.

\section{STRUCTURE AND MAIN ARGUMENTS OF THE MODEL AND ITS HYPOTHESES.}

This model argues for the perspective and view that adopting generalized Darwinism framework should make marketing research more evolutionary and universal. Therefore evolutionary marketing research theory should make a significant optimization of higher marketing ends that is poorly fulfilled so far such as non-linear marketing contributions. Finally, this totally new born marketing philosophy should be expected to work on marketing research panel's data as an empirical context to refine and further developed the proposed integration of Darwinism and marketing research. 
It is contended by this research that encoding marketing problems/ opportunities in to scientific terms should expand variation of marketing ideas. The comprehensive and unstructured nature of the encoding stage ought to be expected to permit for a more extensive of marketing ideas and dimensions to develop, hence making a large pool of marketing potentials and horizons. This ought to lead to the acknowledgment of the multidimensional and highly stochastic nature and substance of most marketing phenomena. There for the carve Lanier and arrangement of lines communicating a marketing phenomenon would defend it against any straight line bias or conventional stereotypical thinking and considering.

The application of scientific research methods to reach scientific marketing solutions ought to result in a selection of the fittest of the large pool of marketing ideas made by the encoding phase. The rigor and majestic substantiation of this stage should create exceedingly grounded and entirely screaming process depending on highly scientific standards and guidelines. Subsequently ruthless exclusion and inclusion process of marketing ideas will take place for filling the guideline and principle of "survival of the fittest" of those thoughts. This phase and it's highly regulars selection mechanism accentuation the relativity of marketing truth. This reflection infers that a marketing insight is resource of interrelated conceptual configuration and empirical test that links many points of comparison. In this way, these linkages keep marketing insights absent from the superficial description of being on one point only leading to unsafe generalizations about the justifications of the levels and extensions of marketing variables.

Decoding of scientific marketing solutions into actionable marketing decisions and polices ought to deliver room for an progressively quickened and dynamic replication process of variation and selection. The goal important highlights of the decoding phase open more venous for future marketing research that points to create indeed more varieties of marketing ideas at the replicated encoding phase. On the other hand the decoding phase revels more suitable measures standards of selection bringing approximately indeed more regress screening and subsequent survival of only the fittest of the fittest of marketing ideas at the applications phase. These replications inevitably result in more proudly elaborate and sophisticated advanced understandings of the substance of marketing phenomena. Furthermore more depth of marketing insights will materialize as more smart linkages between points of signals are found as a result of such replications. Eventually this leads to creating angle expressions of long-term outlook of marketing phenomena that moves away from over streamlined sharp angle extrapolation into more foresightoriented anticipation of the phenomena.

The pervious exploratory research in terms of secondary data analysis and qualitative research with marketing research managers implies an evident policy / practice gap. This gap lies in the limiting ability of marketing research agencies to provide marketing knowledge that can be an opportunity seizer/ problem solver or a unique source of competitive advantage. The clearly evident stereo typical approach of marketing research agencies to conducting panels based research narrows down the possibility to produce real opportunities for competitive superiority. The limited testing power of used statistical technique for selection limits the possibility of reaching out to those opportunities and problems that truly mattered to the majority of customer base. Consequently the highest standardized methodological over dominates of the marketing research process allows little ever creative and iterative replication of the variation and selection process leading to further deprivation of access to real opportunity, problem and competitive 
advantage which erode over time. Thus, totally innovation and ideological approaches such as Darwinism and evolutionary marketing research should help should help in providing true adaptation and feedback to the marketing research process. Even though non-linear marketing and panels are only the empirical context and platform for the ideology of this research, in practical terms they can be thought of as real ground for making greater horizons for new venous of marketing based competitiveness in emerging global, multi-dimension and highly dynamic market places.

The conceptual framework can be argued by this research to bridge a critical research gap that cause for moving into a universe of non-linear marketing, bridging this gap should be expected to secure moving away from the limitations and dangers of straight line, one point and sharp angle illusive prejudices of marketing phenomena, insights and outlooks. The adoption of a generalized Darwinism- supported evolutionary marketing research should provide a strong research initiates for a non-linear market agenda to produce a more realistic, in-depth and forward thinking and doing of marketing phenomena, insights and outlooks. Arguably, improve preventions of marketing as a science and catering for a visible bridging of the gap between marketing theory and practice.

\section{THE CONCEPTUAL FRAMEWORK}

The following figure depicts the proposed conceptual model which is followed by the testable hypotheses expressed by the main argument of this research.

Figure 1: the conceptual model.

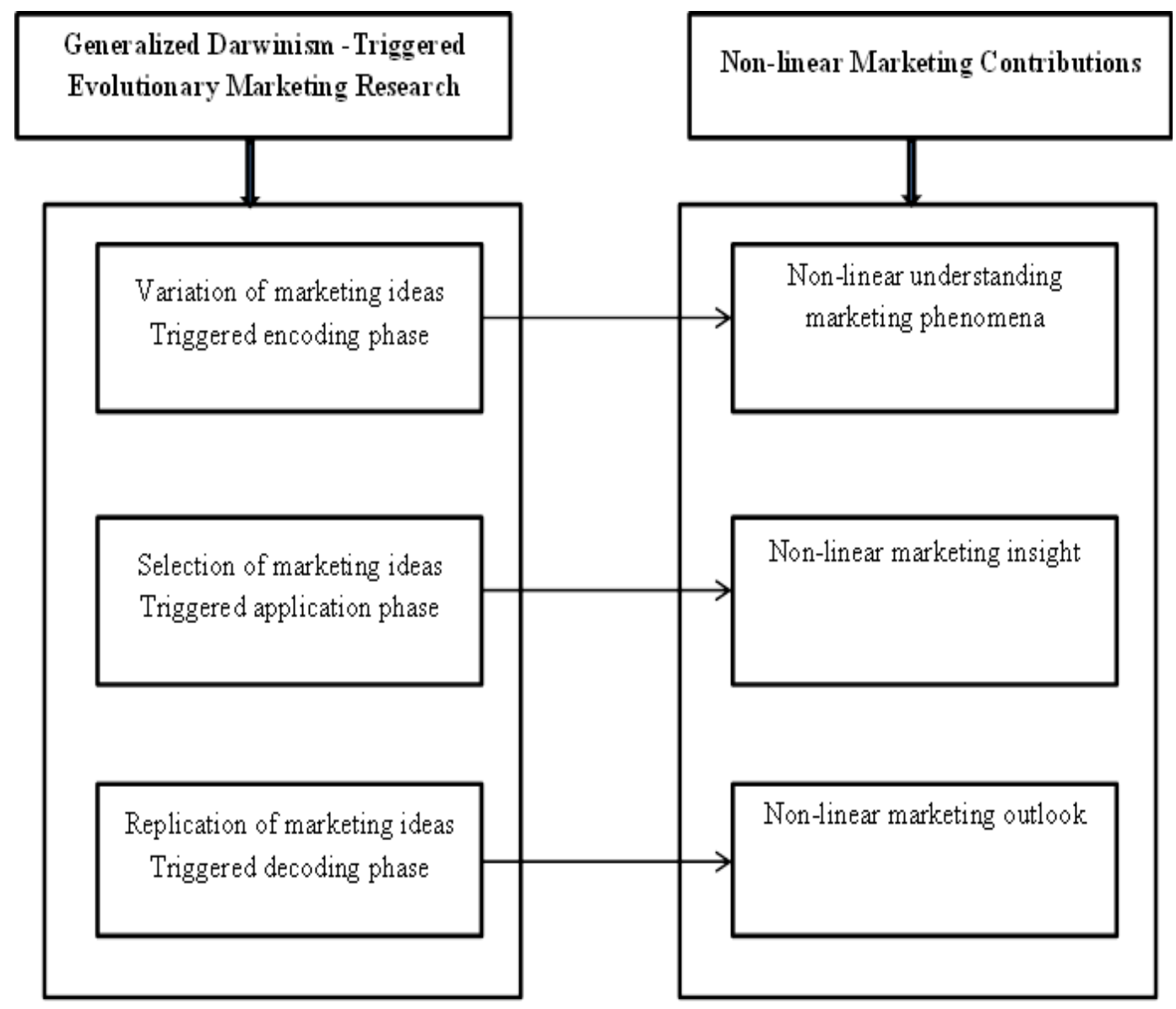

THE HYPOTHESES DEVELOPMENT 
The proposed conceptual framework advocates the following research hypotheses:

H1: variation-triggered-encoding of marketing ideas has a significant and positive impact on nonlinear underlying of marketing phenomena.

H2: selection-triggered-application of marketing methods has a significant and positive impact on non-linear description of marketing insights.

H3: replication-triggered-decoding has a significant and positive impact on non-linear prediction of marketing outlooks.

\section{RESEARCH METHODOLOGY}

The research methodology that adopted in this research used to investigate the research's hypotheses. The following aspects will be discussed;-

\section{Research Design}

Research design is divided into exploratory research design and conclusive causal design:-

1. Exploratory research to define research gap, design conceptual model and formulate research hypotheses consisting of A. analysis of secondary data on the profiles uses and findings of advanced world-wide applications of marketing research panels. B- Qualitative research with concerned parties, in-depth interviews with marketing research managers and marketing researchers on the shop floor in the field to explore when panels are needed and how they are used and the customers short comings and draw backs of prevailing marketing research methodologies and ideologies and how they reflect on the ability of marketing research to provide non-linear outside the box marketing solutions to real marketing problems through adopting truly innovative marketing research philosophies and overall mechanisms like generalized Darwinism based evolutionary marketing research theory.

2. Conclusive causal design which aims to detect, measure and analyze the impact of generalized Darwinism based evolutionary marketing research theory on for-filling through non-linear marketing contributions through a probably equipped marketing research create for marketing research to become an effective problem solver, opportunity seizer and competitive advantage builder and sustainer. The meta-analysis will be the main new design for determining the existence and directions of such causal relationships based on forest plots of a sample of panel-based marketing research reports that seek through insightful and representative measurement of causalities among the independent variables which consolidate the three main underlying dimensions of generalized Darwinism of non-linear marketing contributions. Accordingly this research introduces a methodological contribution through blending a cross-sectional design in terms of industries and countries and longitudinal design in terms of time horizons not in a mutually exclusive sense but in a rare case of integration sense.

\section{Sampling Design and Plan}

The sampling unit for this research would be all panels based marketing research reports on various industrial / organizations, countries/ cultures and time horizons because according to the literature, exploratory those reports are the valid and reliable carriers and containers of the extent of Darwinism/ evolutionary methodologies and non-linear findings and conclusions since it can never be a matter of absolute qualitative facts, preferences or comparisons or perceptions and attitudes rather it has got to be scientific and professional truths judged by the sophisticates mathematical combinations on the comprehensive level and panoramic essence of meta-analysis 
Gad, G., \& Kortaam, W. (2020) Empirical Analysis of a Generalized Darwinism Triggered Theory of Evolutionary Marketing Research. Archives of Business Research, 8(5). 274-297.

originated forest plots ( data about the data) . According to population are all panel based marketing research reports world-wide conductive by professional recognized marketing research firms, teams and consultancies which by definition is an indefinite population that necessitates the use of sampling guide . the sampling guide was secured through the kind and generous approval of A.C-Nelson Egypt top management to provide a fully-scale of such studies conducted by A.C-Nelson as the market leader and best practice benchmark of their studies across the globe. The sample size was mainly determined by the adequacy for analysis and heterogeneity of population across the sampling dimensions of industry, country and time diversity of marketing research projects. These to sample size determination criteria of relative population size and variation of the Darwinism evolutionary phenomena as suggested by the central-limit theorem of longitudinal and cross sectional data. The sampling technique for this research is a genuine cluster sampling of the population away from the conventional wisdom geographical clustering each group of marketing research reports was viewed by the researcher as an internally exhausted and thus ... exclusive cluster of three main categorize of the population in terms of industry classification, country classification and time classification accordingly the sample structure of this research can be expressed as the following portfolio of panel based marketing research reports provided by A.CNelson international through its Egypt branch :-

1. Total number of studies $=86$

2. Industry level sampling structure 50 manufacturing industries and 36 services.

3. Region level sampling structure USA and Canada 20 , Europe 20, MENA 20, Latin \& South America 6 and South Europe\& Asia pacific 20.

4. Time horizon level structure from 1999 to 2000 subtotal ( 26 study), from 2001 to 2010 with subtotal ( 30 study) and 2011 to 2019 with subtotal ( 30 study).

Such sub-sample sizes are considered by meta-analysis as adequate and covering all these sampling selection criteria in a representative way.

\section{Measurement Scaling and Data Collection.}

Ratio scales in the form of a mark of 10 were used to measure all the 9 main variables of this study as expressed by the conceptual model. This was decided as recognition of the essence of variables as quantitative truth measured widely, insightfully and collectively by the unique computation procedures of meta-analysis forest plots. Accordingly 9 ratio scales were developed for the 9 main variables of the model and were fed into the input files of the meta-analysis forest plots as inducted from the marketing research reports by the researcher it can be claimed that those are first time measures to operationalize the newly conceptualize variables of Generalized Darwinism, Evolutionary marketing research and non-linear marketing contributions.

The validity and reliability cannot be tested by the ratio techniques or Cronbach Alpha and factor analysis since interval, ordinal and multi items scales were not be used, so forest plots have the advantages of providing even more rigorous validity and reliability test through the large number of mathematical combination done to calculate forest plots, thus reflecting the true essence (i.e construct validity and consistency (i.e internal consistency reliability) among the great contextual variation exhibited by the carefully and deliberately selected studies.

\section{Research Variables and Measurements}

The Proposed model's variables measurement scales 
Table 1: Developed by the researcher based on conceptualization of literature, qualitative research and analysis of secondary data.

\begin{tabular}{|c|c|}
\hline Variables & Measurement scales as a mark of ten \\
\hline $\begin{array}{l}\text { 1- Darwinism based- } \\
\text { variation }\end{array}$ & $\begin{array}{l}\text { 1-1-Richness of customer links through information variation. } \\
\text { 1-2-Richness of spotting marketing opportunities and problems variations. } \\
\text { 1-3-Richness of marketing performance monitors, evaluations and corrections } \\
\text { variations. } \\
\text { 1-4-Richness of marketing decisions and marketing management quality } \\
\text { standards. } \\
\text { 1-5-Richness of marketing understandings across the organization variations. }\end{array}$ \\
\hline $\begin{array}{l}\text { 2- Darwinism based } \\
\text { selection }\end{array}$ & $\begin{array}{l}\text { 2-1-Rigorous selection of customer links through information. } \\
\text { 2-2-Rigorous selection of marketing opportunities and problems. } \\
\text { 2-3-Rigorous selection of marketing performance monitors, evaluations, and } \\
\quad \text { corrections. } \\
\text { 2-4-Rigorous selection of marketing decisions and management quality } \\
\text { standards. } \\
\text { 2-5-Rigorous selection of marketing understandings across the organization. }\end{array}$ \\
\hline $\begin{array}{l}\text { 3- Darwinism based- } \\
\text { replication }\end{array}$ & $\begin{array}{l}\text { 3-1-Future-oriented and relevant replication of customer links through } \\
\text { information. } \\
\text { 3-2-Future-oriented and relevant replication of marketing opportunities and } \\
\text { problems. } \\
\text { 3-3-Future-oriented and relevant replication of marketing performance monitors, } \\
\text { evaluations and corrections. } \\
\text { 3-4-Future-oriented and relevant of marketing decisions and management } \\
\text { standards. } \\
\text { 3-5-Future-oriented and relevant replication of marketing understandings across } \\
\text { the organization. }\end{array}$ \\
\hline $\begin{array}{l}\text { 4- Evolutionary } \\
\text { encoding }\end{array}$ & $\begin{array}{l}\text { 4-1-Insightful and inclusive definition of marketing research gap. } \\
\text { 4-2-Testability of formulated marketing research questions/ hypotheses. }\end{array}$ \\
\hline $\begin{array}{l}\text { 5- Evolutionary } \\
\text { application }\end{array}$ & $\begin{array}{l}\text { 5-1-Appropriateness of selected marketing research design. } \\
\text { 5-2-Representativeness and magnitudes of sampling design and plans. } \\
\text { 5-3-Validity and reliability of measurement and scaling. } \\
\text { 5-4-Fitness of data preparation. } \\
\text { 5-5-Safe generalization by data analysis. }\end{array}$ \\
\hline $\begin{array}{l}\text { 6- Evolutionary } \\
\text { decoding }\end{array}$ & $\begin{array}{l}\text { 6-1-Action orientation of data interpretation. } \\
\text { 6-2-Foresight of marketing research report preparation and presentation. }\end{array}$ \\
\hline $\begin{array}{l}\text { 7- Non-linear } \\
\text { phenomenon }\end{array}$ & $\begin{array}{l}\text { 7-1-Non-linearity of marketing phenomenon effectiveness. } \\
\text { 7-2-Non-linearity of marketing phenomenon efficiency. } \\
\text { 7-3-Non-linearity of marketing phenomenon adaptability. }\end{array}$ \\
\hline 8- Non-linear insight & $\begin{array}{l}\text { 8-1-Non-linearity of marketing insight effectiveness. } \\
\text { 8-2-Non-linearity of marketing insight efficiency. } \\
\text { 8-3-Non-linearity of marketing insight adaptability. }\end{array}$ \\
\hline 9- Non-linear outlook & $\begin{array}{l}\text { 9-1-Non-linearity of marketing outlook effectiveness. } \\
\text { 9-2-Non-linearity of marketing outlook efficiency. } \\
\text { 9-3-Non-linearity of marketing outlook adaptability. }\end{array}$ \\
\hline
\end{tabular}




\section{Data Analysis}

Descriptive statistics of the sample data will be unusually presented through the means and standard deviations of forest plots according to the three main division pillars of the sample structure. Validity and reliability tests will be reported for each sample according to the forest plots as above explained in the previous section. Meta-regression will be the main statistical technique for hypothesis testing with special focus on analysis outputs of meta intercepts, meta slopes, meta co-efficient of determination $\mathrm{R}^{2}$, meta residuals and meta $\mathrm{t}$ and $\mathrm{F}$ Significance tests. Though the numerical values of the meta-regression looks on surface like the normal multiple regression ones, they are totally much more different and stronger as they are grounded on the highly routed and connected computations of meta-analysis regression mathematical logic.

\section{Descriptive Statistics of Sample Data}

This section will demonstrate the main statistical central tendencies and dispersion of the sample data for the main study variables through the newly developed forest plots instead of the common use of mean and standard deviation. The reason for this un-used expression of sample data trends and patterns is that the use of meta-analysis emphasizes data about data of 86 different immense marketing research reports which means that the use of normal mean and standard division would be totally miss leading. Forest plots were considered as the more accurate reflection of the general trends and patterns of the data as they express the main stream and variations of data about the huge amount and variety of data contained in such diversity of reports. So, descriptive statistics would be presented to reflect the statistical conduct of each proposed model variables and the main categorize of marketing research reports across the criteria that were thought to be relevant to the marketing phenomena under research and its underlying dimensions of Darwinism marketing, evolution marketing and non-linear marketing, all the statistical outputs for that section are presented by the table 2 . 
Table 2 Meta forest plots for descriptive statistics of sampling data

\begin{tabular}{|c|c|c|c|c|c|c|c|c|c|c|}
\hline & \multicolumn{2}{|c|}{ Industry (86) } & \multicolumn{5}{|c|}{ Region ( 86) } & \multicolumn{3}{|c|}{ Time (86) } \\
\hline $\begin{array}{l}\text { Marketing } \\
\text { research } \\
\text { Reports } \\
\text { Variables }\end{array}$ & $\begin{array}{c}\text { Manuf } \\
\text { acturi } \\
\text { ng } \\
(50)\end{array}$ & $\begin{array}{l}\text { Servi } \\
\text { ces } \\
(36)\end{array}$ & $\begin{array}{l}\text { USA \& } \\
\text { Canad } \\
\text { a (20) }\end{array}$ & $\begin{array}{c}\text { MENA } \\
(20)\end{array}$ & $\begin{array}{l}\text { Europ } \\
\text { e (20) }\end{array}$ & $\begin{array}{l}\text { Asia } \\
\text { pacifi } \\
\text { c (20) }\end{array}$ & $\begin{array}{c}\text { Latin } \\
\& \\
\text { South } \\
\text { Ameri } \\
\text { ca (6) }\end{array}$ & $\begin{array}{c}1991 \\
- \\
2000 \\
(26)\end{array}$ & $\begin{array}{c}2001- \\
2010 \\
(30)\end{array}$ & $\begin{array}{c}2011- \\
2019 \\
(30)\end{array}$ \\
\hline $\begin{array}{c}\text { 1- Darwinism } \\
\text {-Based } \\
\text { variation ( } \\
5 \text { ratio } \\
\text { scales) } \\
\end{array}$ & 4.3 & 7.2 & 6.1 & 4.7 & 6.5 & 7.7 & 4.8 & 5.5 & 5.5 & 6.8 \\
\hline $\begin{array}{c}\text { 2- Darwinism } \\
\text {-Based } \\
\text { selection ( } \\
5 \text { ratio } \\
\text { scales) } \\
\end{array}$ & 8.1 & 9.3 & 7.9 & 7.2 & 9.4 & 8.6 & 7.7 & 8.2 & 8.7 & 9.5 \\
\hline $\begin{array}{cc}\text { 3- } & \text { Darwinism } \\
\text {-Based } \\
\text { replication } \\
\text { ( } 5 \text { ratio } \\
\text { scales) }\end{array}$ & 3.8 & 4.5 & 1.8 & 2.5 & 1.9 & 3.1 & 1.3 & 1.7 & 2.2 & 3 \\
\hline $\begin{array}{c}\text { 4- } \\
\text { Evolutiona } \\
\text { ry } \\
\text { Encoding ( } \\
2 \text { ratio } \\
\text { scales) } \\
\end{array}$ & 2.3 & 3.6 & 4.5 & 1.8 & 5.2 & 6.3 & 2.4 & 3.3 & 4.1 & 5.3 \\
\hline $\begin{array}{c}\text { 5- Evolutiona } \\
\text { ry } \\
\text { application } \\
\text { ( } 5 \text { ratio } \\
\text { scales) }\end{array}$ & 7.5 & 7.1 & 9.2 & 8.3 & 8.9 & 7.2 & 6.5 & 7.8 & 8.4 & 8.8 \\
\hline $\begin{array}{c}\text { 6- Evolutiona } \\
\text { ry } \\
\text { Decoding ( } \\
2 \text { ratio } \\
\text { scales) }\end{array}$ & 1.7 & 2.5 & 3.7 & 3.3 & 4.9 & 5.6 & 3.9 & 4.2 & 6.2 & 7.1 \\
\hline $\begin{array}{c}\text { 7- Non-Linear } \\
\text { phenomen } \\
\text { on ( } 3 \text { ratio } \\
\text { scales) }\end{array}$ & 3.2 & 4.4 & 1.3 & 0.8 & 5.1 & 7.4 & 4.8 & 3.3 & 5.6 & 7.4 \\
\hline $\begin{array}{cc}\text { 8- } & \text { Non-linear } \\
\text { insight( } & 3 \\
\text { ratio } \\
\text { scales) }\end{array}$ & 6.8 & 8.2 & 6.6 & 7.2 & 6.6 & 8.5 & 7.1 & 4.7 & 6.8 & 8.3 \\
\hline $\begin{array}{cc}\text { 9- } & \text { Non-linear } \\
\text { outlook( } 3 \\
\text { ratio } \\
\text { scales) }\end{array}$ & 8.4 & 8.6 & 9.1 & 7 & 9.2 & 9.7 & 7.8 & 6.1 & 7.5 & 9.3 \\
\hline
\end{tabular}


Gad, G., \& Kortaam, W. (2020) Empirical Analysis of a Generalized Darwinism Triggered Theory of Evolutionary Marketing Research. Archives of Business Research, 8(5). 274-297.

\section{Generalized Darwinism Variables for Marketing Research}

It is quite evidence that Darwinism-based selection proved to be the highest relevant trend among the three Darwinism variables with an average of eight out of ten for all marketing research reports. This assures the prediction and common findings that most marketing research efforts and focus emphasizes the professionalism of doing a more and more rigorous selection of all possible marketing research variations in each report. This is clearly obvious specially across time which means the continuous advanced academic and professional marketing research are reaching high levels of rigorous refinement and substantiation of marketing phenomena with the easily observable knowledge explosion of the area of marketing research. On the other hand as far as industry is concerned the selection process is significantly more rigorous in service rather than manufacturing industries. This can be due to the less precise, highly varied and more risky nature of marketing variables and phenomena within the context of service in organizations and markets due to their intangibility and perishability. On the other hand the rigor of the selection process seems to be in its highest level of maturity followed by Asia and Pacific markets due to their sever competition, while its considerably less in North American, MENA and south America markets due to their growing and emerging stages.

Darwinism-based variation came second but, considerably behind selection which means that less attention is paid at the exploratory phase of marketing research is taking to more well-tested assumptions and stereotypes about marketing phenomena. Variations of marketing research themes and Venues have witness only moderate improvement in the last decade while being stable through the first two decades. This can be explained by the failure of a large number of marketing research solutions that can be too limited variation of marketing opportunities and problems. It is quite clear that while variation is practiced widely for service organizations as reflected by service innovation across the world. The amount of variation was at its highest levels in Asia Pacific, Europe and North American markets indicating the high levels of opportunity services marketing thinking in these regions with implications to their competitive advantage. The variation variable has shown minimum levels in the MENA region and South America markets which explicitly highlight that these markets still has lots of emerging opportunities if proper levels of variationbased-marketing innovation are fulfilled.

Darwinism based replication proved to be the lowest variable across all the marketing context of this research. The overall average of replication never exceeded the level of 2.2 at any point in time, place and industry compared to eight in the case of selection and six in the case of variation is considered even so unnoticed this clearly argues that marketing researchers take any little time and effort to learn, let alone apply any future lessons and values for their forthcoming marketing research projects. Despite the fact that replication very slow and minor from one decade to another, the replication has shown its relatively highest level across industries with more future orientation for marketing research directly to the service organizations reflecting in the higher level of market turbulence for customer bases of such industries. The future orientation of the replication variable proved to be terribly low across all regions of the world with only slight rise in the MENA and Asia Pacific markets indicating greater concerns of marketing researchers about the future and their drastic flip flubs and Zigzags within the foreseeable future. 


\section{Evolutionary Marketing Research Variables}

The same story of the descriptive statistics of patterns and trends about Darwinism variables can be almost identically told about evolutionary marketing research variables. This very important associations in behavior between Darwinism variables and Evolutionary marketing research variables tentatively argues strongly for the main configuration of the proposed model integrating the Generalized Darwinism paradigm into the evolutionary marketing theory with a clear augmented and triggering implications and contributions as selection proved to be the highest Darwin variable within an average of 8 the application variable have shown the same level with the same average, not only that but also, evolutionary application have shown the same data patterns across time and regionals contexts the only difference appeared in the more rigorous application in manufacturing industries probably expressing a greater accumulation of academic and professional best practices of marketing research. The same can be observed about the levels of Darwinism variation and evolutionary encoding but with a lower average of encoding which is five compared with the level of six of variation, Other than that Evolutionary encoding has shown the same level, patterns and trends across various time horizons industries and regions. This implies again that because of limited variation marketing researchers do not take adequate time and effort to focus on variation oriented exploratory marketing research. Actually in some marketing research reports there were no traces of exploration, thus encoding is gone with the wind, unfortunately evolutionary decoding have exhibited the same destiny as Darwinism replication with an average level of 3.5 which could be considered considerably higher the 2.2 of replication but yet much lower than expected for such a vital future driven marketing research phase. The main pattern of decoding matched that of replication across industries and regions, but with an important rise across time horizons which could imply that marketing researchers are realizing the growing importance of interpreting and reporting their findings and contributions in a more understandable decision maker friendly fashion.

\section{Non-Linear Marketing Variables}

The first surprising findings of that research, yet quit meaningful was the unpredictably very high level of non-linear marketing outlook in spite of the relatively weak levels of the driving variable of Darwinism replications and evolutionary decoding. From the researcher's point of view this does not negate the impact of replication and decoding on outlook as much as it shows the multiplier effect of replication and decoding on the forecasting power of marketing research to possess an outlook of marketing phenomena with an average level of 8.5 which the highest among all variables. Non-linear insight with an average of 7 clearly followed the same high levels of selection and application expressing the positive and effective influence of rigor of marketing research process to provide in-depth comprehension of marketing deep dimensions. The same can be argued for non-linear phenomena with an average of 4.7 responding quite proportionately to the patterns of variation and encoding precisely across all time horizons industries and regions.

To wrap-up the fact that the levels of forest-plots show some level of decrease as they move from Generalized Darwinism variables to evolutionary marketing research variables to non-linear marketing variables can be explain by arguing that either there are other un-known variables reflecting the influences across the process or that the management of marketing research processes does not embrace and emphasize sufficiently the ideology of Generalized Darwinism into the process of evolutionary marketing research as consequential on non-linear marketing agenda. Thus, depriving marketing research theory and practice from a very promising association that can 
Gad, G., \& Kortaam, W. (2020) Empirical Analysis of a Generalized Darwinism Triggered Theory of Evolutionary Marketing Research. Archives of Business Research, 8(5). 274-297.

revolutionized the way marketing research is used to make a strong impact on vital marketing agendas.

\section{Contextual Variables of Industry, Geography and Time}

Descriptive statistics in the form of meta-forest plots are also quite indicative of the three universal contexts selected by the researcher as platforms in which the proposed model exist and operates. The first context which is manufacturing versus service industries shows that service industries in general with few exceptions are significantly more receptive and responsive to the main underlying logic of the proposed model.

The selection $\rightarrow$ application seem to be much more evident to be managed deliberately and intensively by the service organizations than manufactures even the replication $\rightarrow$ decoding which is generally low across both categories of industries still much greater in service industries than manufacturing ones. There are two possible explanations for this meaning forward discrepancy, the first explanation is the severe competition and lack of competitive advantage in the form of patterns among service brands which create a more risky and highly changing marketing environment for those organizations which make them need more evolving and futureoriented marketing research, The second explanation is that the mindsets of marketers in service industries are more time sensitive and opportunity seeking than those marketers of manufacturing organizations due to the emerging and less matured nature of service markets which makes reliance on loose and creative marketing research more of an action than an option.

On the other hand, the geographical distribution of marketing research projects reflect quite an interesting exploration of the global practices of advanced marketing research, the more saturated and efficient European markets and a clearly fast emerging and untapped of MENA and Asia Pacific regions calls for a clear inclination to think and practice marketing research in a greater innovative and breakthrough formats. This is even also more true in the less practiced and considered phases of replication $\longrightarrow$ decoding. The more standardized marketing oriented environments of north and South Americans indicate less awareness and accordingly less exercise of un used and outside the box marketing research practices.

The alarming issue is that all regions are obviously more directed to non-linear outlooks in the final analysis despite weak replication $\longrightarrow$ decoding levels and less oriented to fulfilling higher interest of marketing insights and phenomena understanding despite greater concerns and focus on selection $\rightarrow$ application and variation $\longrightarrow$ encoding. The unfavorable interpretation of these figures is that the technical and scientific quality of marketing research reports are more emphasized than the critical marketing agenda of marketing organization across the world so, is litter wander that global marketing strategies a frequently suffer strong cases of marketing failures and crisis specially in the long run.

As far as the time context is concerned, it seems that the future holds great promise for the proposed model and all other models regarding to the interdisciplinary school of marketing thought. There is evidently a persistent and favor escalating concern and investment in improving the 3 main phases of marketing research process and achieving higher levels of far reaching ends of marketing thinking and doing like non-linear agendas. The interdisciplinary mindsets would keep the marketing research process equipped with the depth and breadth to progress infinitely 
over these new fronts taking marketing research into new horizons to accomplish more and more of such high marketing ends. The clear indicator of this is the commitment of marketing organizations across all industries and regions to achieve more ambitious end of marketing outlooks despite the relatively low level of their consequently replication-decoding toolsets.

\section{Testing the Validity and Reliability of Main Proposed Model Variables}

This section aims to provide the statistical index of validity and reliability of the used ratio scaled to measure the main independent and dependent variables of the proposed model. Again, inventively adoption of meta-forest plots will used to test mainly two kinds of validity and reliability, the construct validity cannot be over emphasized for this research due to the total newness to the independent and dependent variables. Thus, the independent variables are integrated into three main variables resulting from intermingling Generalized Darwinism variables with evolutionary marketing research variables resulting in three main independent variables that reflect the core of the proposed model's token and argumentation, namely they are; 1 - variation triggered encoding, 2- selection triggered application and 3-replication triggered decoding. The dependent variables manifesting the higher marketing ends of non-linear marketing remain the same as they are already fully conceptualized by the cited non-linear marketing literature. There for table 3 reflect the meta-forest plots for construct validity of the model core variables with the last three rows assuming the same values for the dependent variables as exactly depicted by table 2 .

Table 2 Meta forest plots for Validity and Reliability of main factors

\begin{tabular}{|c|c|c|c|c|c|c|c|c|c|c|}
\hline & \multicolumn{3}{|c|}{ Industry (86) } & \multicolumn{4}{|c|}{ Region ( 86) } & \multicolumn{3}{|c|}{ Time (86) } \\
\hline $\begin{array}{l}\text { Marketing } \\
\text { research } \\
\text { Reports } \\
\text { Factors }\end{array}$ & $\begin{array}{l}\text { Manu } \\
\text { factu } \\
\text { ring } \\
(50)\end{array}$ & $\begin{array}{c}\text { Servi } \\
\text { ces } \\
(36)\end{array}$ & $\begin{array}{c}\text { USA } \\
\& \\
\text { Cana } \\
\text { da } \\
(20)\end{array}$ & $\begin{array}{c}\text { MEN } \\
\text { A } \\
(20)\end{array}$ & $\begin{array}{c}\text { Euro } \\
\text { pe } \\
(20)\end{array}$ & $\begin{array}{l}\text { Asia } \\
\text { pacifi } \\
\text { c } \\
(20)\end{array}$ & $\begin{array}{l}\text { Latin } \\
\& \\
\text { South } \\
\text { Ameri } \\
\text { ca (6) }\end{array}$ & $\begin{array}{c}1991 \\
- \\
2000 \\
(26)\end{array}$ & $\begin{array}{c}2001 \\
- \\
2010 \\
(30)\end{array}$ & $\begin{array}{c}2011 \\
- \\
2019 \\
(30)\end{array}$ \\
\hline $\begin{array}{l}\text { 1- Variation- triggered } \\
\text { Encoding ( } 7 \text { Ratio } \\
\text { scales) }\end{array}$ & 5.5 & 5.1 & 6 & 4.3 & 6.3 & 7.5 & 4.9 & 3.8 & 5.3 & 4.5 \\
\hline $\begin{array}{l}\text { 2- Selection-triggered } \\
\text { application ( } 10 \\
\text { Ratio scales) }\end{array}$ & 8.8 & 9.3 & 8.1 & 7.5 & 9.1 & 9.4 & 7.6 & 8.5 & 9 & 9.6 \\
\hline $\begin{array}{l}\text { 3- Replication- } \\
\text { triggered Decoding ( } \\
7 \text { Ratio scales) }\end{array}$ & 1.4 & 3.2 & 3.6 & 3.7 & 3.2 & 5 & 1.1 & 3.3 & 3.1 & 2.8 \\
\hline $\begin{array}{l}\text { 4- Non-linear } \\
\text { phenomenon ( } 3 \\
\text { Ratio scales) }\end{array}$ & 3.2 & 4.4 & 1.3 & 0.8 & 5.1 & 7.4 & 4.8 & 3.3 & 5.6 & 7.4 \\
\hline $\begin{array}{l}\text { 5- Non-linear Insight (3 } \\
\text { Ratio scales) }\end{array}$ & 6.8 & 8.2 & 6.6 & 7.2 & 6.6 & 8.5 & 7.1 & 4.7 & 6.8 & 8.3 \\
\hline $\begin{array}{l}\text { 6- Non-linear outlook } \\
\text { (3 Ratio scales) }\end{array}$ & 8.4 & 8.6 & 9.1 & 7 & 9.2 & 9.7 & 7.8 & 6.1 & 7.5 & 9.3 \\
\hline
\end{tabular}


Gad, G., \& Kortaam, W. (2020) Empirical Analysis of a Generalized Darwinism Triggered Theory of Evolutionary Marketing Research. Archives of Business Research, 8(5). 274-297.

By the same sense, internal consistent reliability was concerned the most important kind of reliability test because of the rate variation of time, industry and geography context in which the model will be empirically test.

Accordingly the consistency of differences among the variables for the sake of reliable hypotheses testing was inevitably so, this section is consist two main parts; the first for testing construct validity and second part will be devoted to test internal consistent reliability.

The comprehensive meta-analysis -CMA / AMOS- software used for computing all the metaanalysis outputs for this research assures the face validity and discriminate reliability as ground for ensuring more advanced test of validity and reliability as those reporting by the next two subsections. Comprehensive Meta-Analysis (CMA) is a software that can be utilized to conduct a metaanalysis essentially and effectively. It permits the researcher to compute the effect size for each study automatically and make high-resolution forest plots and includes a extend of advanced features.

\section{Construct Validity of Measuring the Proposed Model's Variables}

As an overall assessment of the construct validity of all the variable composing the proposed model, it can be argued that all the 6 dependent and independent variables has shown quite high levels of forest-plots which is statistically acceptable at the level of 2 . Most variables have shown an average level of 5 to 8 except the forest plots of the replication triggered decoding independent variable for manufacturing industries and the Latin south American regions and the dependent non-linear phenomena variable for the USA and Canada and MENA regions. This is understandable and expected to a large extent due to the general limited practice of the replication triggered variable with special reference to manufacturing industries and by the Latin in south American marketing research industry. The same can be argued about the pursuit of non-linear phenomena agenda by American and MENA regions companies and their hired marketing research firms.

The selection triggered application has shown the highest level of construct validity which again indicates the deliberately and plans high levels of in acting the ideology of Darwinism selection for the sake of rigorous application across all the context of this research. This was followed by a difference of magnitude by the variation triggered encoding indicating the significant concern of devising Darwinism variation to support comprehensive evolutionary encoding of the marketing research process across all context of this research. But, with a less awareness and subsequently intensity of those practices of Darwinism selection and its counterpart evolutionary application. The replication triggered decoding achieved a low but acceptable level of construct validity with a significant difference below the two other independent variables, thus demonstrating the relatively limited regard for making Darwinism replication a positive impetus for evolutionary decoding across all context of research and with special weakness for manufacturing industries as above explained. The average value of forest plots were 8.2 , 5.7, 3.1 for the independent variables of selection triggered application, variation triggered encoding and replication triggered decoding respectively.

On the other hand, surprisingly unlike the independent variables, the dependent variables of nonlinear outlooks proved to be the highest in construct validity among all other dependent variables which reflects the importance and perceiving seriousness of making accurate ambusions by yet 
realistic forecasting of future marketing phenomena among all the marketing research stakeholders and providers operating a cross the various context of this research. Understandably and expectedly non-linear insight has shown a high level of construct validity due to the longstanding and well-established conceived need to have in-depth understanding of marketing constructs and variables for marketing decision makers and their hired marketing research firms in response of the highly turbulent context in which they are competing, also surprisingly the nonlinear phenomena dependent variable has exhibited the lowest level construct validity with even in valid levels into regions as above explained, reflecting the relatively low level of marketing research attention to explain the non-linear features of marketing phenomena to marketers, thus taking the round-the-corner comfort zone of linear diagnosis and solutions. The average level of construct validity forest-plots were $8.5,7.7$, and 5 for non-linear outlook, non-linear insight and non-linear phenomena dependent variables respectively.

\section{Internal Consistency Reliability for Proposed Model Variables}

A similar argument can be made when evaluating the internal consistency reliability for the proposed models independent and dependent variables relying on the same forest-plots and their average levels for the 6 independent and dependent variables it can be strongly indicated that a highly acceptable level of internal consistency reliability is evident for all variables with the exception of the same three cases highlighted for construct validity. So, it can be contributed that selection triggered application consistently reflect the variation in practicing rigorous selection and application, followed by variation triggered encoding for comprehensiveness of marketing research process and replication triggered decoding for relevance respectively.

Internal consistency forest-plots for the dependent variables are also shown that non-linear outlook was the highest in reflecting the differences among all research contexts in aiming to predict a marketing future followed by non-linear insight for the sake of real substance of marketing construct and variables to be followed by the least level of seeking non-linear phenomena for the sake of non-linear realistic understanding of critical and multi-dimensional marketing phenomena across all the various context in which the proposed model was empirically tested.

\section{Hypotheses Testing of the Proposed Model}

Meta-Regression equations were developed to test each one of the research hypotheses. Table 4.3 and its subsequent equations and variable coding depicities the outputs of all three metaregression regression. Equation one expresses non-linear phenomena as the dependent variable and the three Darwinism triggered evolutionary marketing research variables as the independent variables. This equation has shown a relatively high level of fitness of model as indicated by the outputs of $\mathrm{F}$ test. The adjusted $\mathrm{R}^{2}$ which is $56 \%$ though the lowest among the three equations is still a very strong indicator that the three independent variables provide good exploratory power of the variations in non-linear phenomena according to Darwinism triggered evolutionary marketing research. The negative level of intercept for this equation implies that the absence of the proposed model Darwinism evolution ideology could only result in straight line configuration of marketing phenomena. The most significant determinants of non-linear phenomena is selection triggered application followed by variation triggered encoding and finally replication triggered decoding based on the slope and T test computations. Thus, hypothesis one cannot be rejected 
Equation two shows an even higher level of fitness of model according to the $\mathrm{F}$ test which means that non-linear insight can be realistically explained by the exercise of Darwinism triggered evolutionary marketing research. The adjusted $\mathrm{R}^{2}$ is also higher for equation two than equation one explaining $63 \%$ of the variation in non-linear insights that can be explained by three Darwinism triggered evolutionary marketing research variables which is again a considerable level of explanatory power. Another negative value of the intercept of this equation clearly indicates that the depth of understanding marketing insights cannot be compromised without the strong presence of Darwinism triggered evolutionary marketing research ideological tools. The most significant determinates of non-linear insight was also selection triggered application followed closely by variation triggered encoding and finally from a statistical distance replication triggered decoding according to the slopes and T test outputs of this equation respectively. Thus, hypothesis two cannot be rejected.

The real novice contribution of this research is served by the third equation showing that in general despite the very limited conceptualization and practice of the three Darwinism triggered evolutionary marketing research variables for future purposes, the equation has shown the highest level of power of magnitude i.e influence on its dependent variable of non-linear outlook. The interesting finding by this token is that non-linear outlook is the most sensitive to even the lowest level of practice of Darwinism triggered evolutionary marketing research which reflects a very strong association between the ideological wings of the model and its far reaching destination. In retrospect the $\mathrm{F}$ test for this equation have shown the highest level of fitness of model emphasizing the strong loyalty of the relationship between non-linear outlook and the pursuit of Darwinism triggered evolutionary marketing research. Another confirmation of this conclusion is also the adjusted $\mathrm{R}^{2}$ of $65 \%$ expressing the highest explanatory power of all non-linear outlook by the three Darwinism triggered evolutionary marketing theory independent variables. The meta-regression intercept was highly negative showing that without a clear ideology of Darwinism triggered evolutionary marketing research, realistic marketing dreams terns into disappointing wishful marketing thinking.

In consistency with the order of power of magnitude for the three determinants of non-linear outlook, selection triggered application proved to be the most influential followed by variation triggered encoding and finally replication triggered decoding according to the slopes and $\mathrm{T}$ statistic outputs respectively Thus, hypothesis three cannot be rejected. 
Table 4 Meta Regression output for hypotheses testing

\begin{tabular}{|c|c|c|c|c|c|c|c|c|}
\hline \multirow[b]{2}{*}{ Equation } & \multirow{2}{*}{$\begin{array}{c}\text { Depend } \\
\text { ent } \\
\text { variabl } \\
\text { e }\end{array}$} & \multirow[b]{2}{*}{ A } & \multicolumn{3}{|c|}{ Independent variables } & \multirow{2}{*}{$\begin{array}{l}\text { Adjust } \\
\text { ed } R^{2}\end{array}$} & \multicolumn{2}{|c|}{ f } \\
\hline & & & $\begin{array}{c}\mathrm{X}_{1} \\
\text { B1 }\left(\operatorname{sig} \mathrm{t}_{1},\right. \\
\left.\mathrm{t}_{1}\right)\end{array}$ & 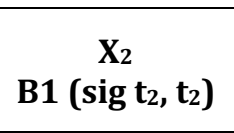 & $\begin{array}{c}X_{3} \\
\text { B1 }\left(\operatorname{sig~t} t_{3}, t_{3}\right)\end{array}$ & & $\operatorname{Sig} \mathrm{f}$ & f \\
\hline One & $Y_{1}$ & -1.3 & $\begin{array}{c}3.1(7.33,3.2 \\
2)\end{array}$ & $4.3(6.25,1.12)$ & $2.2(4.11,0.82)$ & 0.56 & 5.7 & 12.2 \\
\hline Two & $\mathbf{Y}_{2}$ & -1.2 & $\begin{array}{c}4.3(6.51,3.3 \\
1)\end{array}$ & $5.1(7.1,1.2)$ & $1.8(5.3,2.1)$ & 0.63 & 0 & 9.8 \\
\hline Three & $\mathbf{Y}_{3}$ & -3.3 & $3.1(5.1,1.1)$ & $4.1(4.8,0.5)$ & $\begin{array}{c}1.17(4.33,2.65 \\
)\end{array}$ & 0.65 & 0 & 10.11 \\
\hline
\end{tabular}

Such That

$\mathrm{Y} 1=\mathrm{a} 1+\mathrm{B} 1 \mathrm{X} 1+\mathrm{B} 2 \mathrm{X} 2+\mathrm{B} 3 \mathrm{X} 3+\mathrm{E} 1$

$\mathrm{Y} 2=\mathrm{a} 2+\mathrm{B} 1 \mathrm{X} 1+\mathrm{B} 2 \mathrm{X} 2+\mathrm{B} 3 \mathrm{X} 3+\mathrm{E} 2$

$\mathrm{Y} 3=\mathrm{a} 3+\mathrm{B} 1 \mathrm{X} 1+\mathrm{B} 2 \mathrm{X} 2+\mathrm{B} 3 \mathrm{X} 3+\mathrm{E} 3$

Where

Y1 = Non-linear phenomenon

Y2= Non-linear Insight

Y3= Non-linear outlook

$\mathrm{X} 1=$ Variation-Triggered-Encoding

X2Selection-Triggered-Application

X3= Replication-Triggered-Decoding

This chapter has clarified the statistical performance and power of the proposed model empirically through intensive testing of all its aspects with the innovative use of meta-analysis detailed metaanalysis forest-plots were used to describe sample data of all individual variables of this model instead of the conventional use of mean and standard deviation. More integrated calculations of forest-plots of the dependent and independent variables of the model have shown highly acceptable levels of construct validity and internal consist reliability of the measurement scales for the proposed model core variables instead of the usual reliance on Cornbach Alpha and factor analysis. The meta-regression was used to test the research hypotheses and provided a highly effective articulation of their fitness of model ,intercept, explanatory power, slopes and $\mathrm{T}$ test significance of the impact full dependence of non-linear marketing agenda on the extent of adopting and in acting an ideological theory of Darwinism triggered evolutionary marketing research.

\section{Section one: Theory Implications}

\section{THE IMPLICATIONS OF THE RESEARCH}

There are three main theory implications that can be safely generalized by this research first, interdisciplinary marketing research is moving quickly away from being an intellectual luxury to being un avoidable mandate for a more promising destiny of marketing as a science and as managerial practice. This research can be claimed to be the sequel of few ones who tried to 
Gad, G., \& Kortaam, W. (2020) Empirical Analysis of a Generalized Darwinism Triggered Theory of Evolutionary Marketing Research. Archives of Business Research, 8(5). 274-297.

empirically measure the contribution of using theories from other disciplines to achieve critical and contemporary marketing agendas. This research is argued to be a good example of using a theory from a discipline that looks very different from marketing in its conceptual roots and postulates, research agenda, methodologies and resulting scientific truth. Yet, this research has shown how the science of biology, for example and its paradigms and theories can help in developing new marketing tools that can achieve un precedent levels of marketing contributions to significant agendas.

Finding new venues for marketing to improve its credentials as a science and bridge the gap between marketing theories and practice entails either using advanced other physical and social sciences tool to achieve marketing objectives ( like this research) and or use advanced marketing tools to achieve the academic goals of other sciences or to give birth to totally new interdisciplinary sciences.

Second, there were earlier adoptions of Darwinism in marketing thought as evident in the literature review but this research can claim that it is using Darwinism in three new manners:- 1use of Generalized Darwinism 2- looking at Generalized Darwinism from various scientific perspectives in economics, sociology, psychology and 3- serious and rigorous empirical testing of Darwinism ideology on a marketing research theory. The empirical findings have shown very significant support for the proposed model sending a cross the message that the evolutionary philosophy of Generalized Darwinism catered for an evolutionary theory of marketing research that made its process flexible, evolving and consequential enough to achieve higher marketing ends such as non-linear marketing agendas.

Third, not only that interdisciplinary research is not adequate practice into marketing research but also, there are important marketing tools and context that are not capitalized on to improve our academic understanding of marketing phenomena. This research has shown that using such tools and context can make a visible difference and shift in marketing thinking through more effective and planned use of one of :- 1- ubiquitous marketing research 2- marketing research panels and 3- non-linear marketing philosophy.

\section{Section two:- policy implications}

The main policy implications resulting from this research can be also, expressed in three main points first; managing marketing research professionally needs to be not only methodological ( the know- how) but also, ideological ( the know-why). Adopting advancing ideologies such as Generalized Darwinism and evolutionary marketing research can help marketing research agencies respond more quickly and effectively to the needs of their client organizations . thus, making the value added of marketing research more visible. Second; marketing research agencies are aware of the need to vary and yet standardized the marketing research process through different context with special emphasis on geography, industry and time. The marketing research process is not only evolutionary from insight from one step to another, but also from outside from one context to another. Third, the marketing research industry has to learn, unlearn and relearn new marketing research techniques or redefine them (like marketing research panels) to respond to the growing demands of its customer base. The marketing research industry does not live a safe Heaven protected from alternative total solutions such as big data, analytics and artificial marketing intelligence. 


\section{RECOMMENDATIONS FOR FURTHER RESEARCH}

As argued by Kortam and Gad (2018) and further support by this research if marketing scholars hold a strong belief in making marketing research more effective through a quantum leap of making it deliberately and geometrically philosophical, ideological and interdisciplinary at least three brave frontiers can be immediately tackled:- 1- inaugurating a Socratic school of marketing thinking for argumentation (Elenchus in ancient Greek ) 2- devising a Descartes' critical rationalizes as a new discourse of marketing research methodology (Discourse de la method in French) 3- developing an Enstine's analogy of a general relativity theory of marketing research through the marketing dualistic metaphors of place for market, time for customer life time , man for brand and mass for value.

\section{References}

1. Aldrich, H.E. (1999). Organizations Evolving. London: Sage.

2. Aldrich, H. E., Hodgson, G. M., Hull, D. L., Knudsen, T., Mokyr, J., \& Vanberg, V. J. (2008). In defence of generalized Darwinism. Journal of Evolutionary Economics, 18(5), 577-596. https://doi.org/10.1007/s00191-008-0110-z.

3. Andersson, C (2011) Splitting the replicator: Generalized Darwinism and the place of culture in nature. J Econ Behav \& Org 80: 657-669, DOI: 10.1016/j.jebo.2011.06.027.

4. Barnett, W. A., (1996), Commerce, Complexity and Evolution: Topics in Economics, Finance, Marketing and Management, Google Books.

5. Breslin, D. (2008). A review of the evolutionary approach to the study of entrepreneurship. International Journal of Management Reviews, 10, pp. 399-423. https://doi.org/10.1111/j.1468-2370.2008.00234.x

6. Breslin, D. (2010). Generalising Darwinism to study socio cultural change. International, Journal of Sociology and Social Policy, 30, pp. 427-439. https://doi.org/10.1108/01443331011060760.

7. Breslin, D (2011), Reviewing a Generalized Darwinist Approach to Studying Socio-Economic Change. Int J Man Rev 13: 218-235. https://doi.org/10.1111/j.1468-2370.2010.00293.x.

8. Brittain, J.W. and Freeman, J.H. (1980). Organizational proliferation and density dependent selection. In Kimberley, J. and Miles, R. (eds), The Organizational Life Cycle. San Francisco, CA: Jossey-Bass, pp. $291-338$.

9. Buenstorf G (2006) How useful is generalized Darwinism as a framework to study competition and industrial evolution? J Evol Econ 16(5):511-527. DOI: 10.1007/s00191-006-0035-3.

10. Campbell, DT (1960) Blind Variation and Selective Retention in Creative Thought as in other Knowledge Processes. Psych Rev , 63(5), 330-342. http://dx.doi.org/10.1037/h0047553.

11. Campbell DT (1965) Variation, selection and retention in sociocultural evolution. In: Barringer DR, Blankstein GI, Mack RW (eds) Social change in developing areas: a reinterpretation of evolutionary theory. Schenkman, Cambridge, MA, pp 19-49.

12. Chiou, Jyh-Shen and Pan, Lee-Yula, (2008), The Impact of Social Darwinism Perception, Status Anxiety, Perceived Trust of people and cultural orientation on Customer Ethical Beliefs, Journal of Business Ethics, Volume 7, Number 8, PP: 487502. DOI 10.1007/sl0551-007-9364-X.

13. Cherry, Kendra. "What Is Longitudinal Research?". Experiments. About.com guide. Retrieved 22 February 2012.

14. Cordes C (2006) Darwinism in economics: from analogy to continuity. J Evol Econ 16(5):529-541. D0I: 10.1007/s00191-006-0027-3. DOI 10.1007/s00191-006-0027-3

15. Cordes, C (2009) The role of biology and culture in Veblenian Consumption Dynamics. JEcon Issues 43: $115-141$. https:// doi/abs/10.2753/JEI0021-3624430106. 
Gad, G., \& Kortaam, W. (2020) Empirical Analysis of a Generalized Darwinism Triggered Theory of Evolutionary Marketing Research. Archives of Business Research, 8(5). 274-297.

16. Daniels, S and Martin, J., (1999), "It Is Darwinism - Survival of The Fittest - How Markets and Reputation Shape the Ways in Which Plaintiffs" Lawyers Obtain Clients, Law and Policy, Volume 21, Issue 4, PP: 377399. https://doi.org/10.1111/1467-9930.00078.

17. Darwin, C.R. (1871). The Descent of Man and Selection in Relation to Sex, 1st edn. London: John Murray.

18. Dawkins, R. (1976). The Selfish Gene. New York: Oxford University Press.

19. Dawkins, R (1983) Universal Darwinism. In: Bendall, DS (ed.) Evolution from molecules to man. Cambridge University Press, Cambridge, pp. 403-425.

20. Dennett, DC (1994) Darwin's Dangerous Idea. Simon \& Schuster, New York. DOI. 10.1086/233714.

21. Drozdenko, R.G. and Drake, P.D. (2002), Optimal Database Marketing, Sage, Beverly Hills, CA.

22. Frees, E. (2004). Longitudinal and Panel Data: Analysis and Applications in the Social Sciences. New York: Cambridge University Press. DOI: 10.2307/30047489.

23. Gunn, B., (1969), Applying Systems Perspective to Marketing Motivation, European Journal of Marketing, Volume 3, Issue 1, PP: 18-31.

24. Hannan, M.T. and Freeman, J. (1977). The population of ecology of organization. American Journal of Sociology, 82, pp. 929-964.

25. Haring, Albert. (2016), the evolution of marketing research techniques, American marketing association.

26. Hax, A.C. and Wilde, D.L. III (2001), The Delta Project, Palgrave, New York, NY, pp. 63-80.

27. Hodgson, G. (2003). The mystery of the routine: the Darwinian destiny of an evolutionary theory or economic change. Revue Economique, 54, pp. 335-384. https://doi.org/10.3917/reco.542.0355.

28. Hodgson, G. (2005). Generalizing Darwinism to social evolution: some early attempts. Journal of Economic Issues, pp. 899-914. https://doi.org/10.1080/00213624.2005.11506859.

29. Hodgson, G. and Knudsen, T. (2004). The firm as an interactor: firms as vehicles for habits and routines. Journal of Evolutionary Economics, 14, pp. 281-307. DOI: 10.1007/s00191-004-0192-1.

30. Hodgson, G.M. and Knudsen, T. (2006). Dismantling Lamarckism: why descriptions of socio-economic evolution as Lamarckian are misleading. Journal of Evolutionary Economics, 16, pp. 343-366. DOI 10.1007/s00191-0060019-3.

31. Hodgson, G.M. and Knudsen, T. (2010). Darwin's Conjecture: The Search for General Principles of Social and Economic Evolution. Chicago, IL: University of Chicago Press.

32. Hodgson GM, Knudsen T (2006), Why we need a generalized Darwinism: and why a generalized Darwinism is not enough. Journal of Economic Behavior and Organization 61(1):1-19. doi:10.1016/j.jebo.2005.01.004.

33. Hull, DL (1988), Science as a Process. An Evolutionary Account of the Social and Conceptual Development of Science, University of Chicago Press, Chicago and London. https://doi.org/10.1046/j.14209101.1990.3030311.x.

34. Hull, DL (1989), the Metaphysics of Evolution. State University of New York Press, Albany.

35. Institutions: A Critical Reader, (Cheltenham, UK: The European Association for Evolutionary Political Economy and Edward Elgar Publishing Limited Company), Last login jan,2019.

36. Jones, S.K. (2006), Creative Strategy in Direct \& Interactive Marketing, 3rd ed., Racom Communications, New York, NY.

37. Kask, J., (2013), On Business Relationships as Darwinism Systems: An Exploration Into How Darwinism Systems Thinking Can Support Business Relationships, Orebro University School of Business, Sweden.

38. Knudsen, T (2004) Economic Evolution without Variation, Selection and Retention. Erwägen - Wissen - Ethik 15: 75-78. http://hdl.handle.net/10419/32647. 
Archives of Business Research (ABR)

Vol.8, Issue 5, May-2020

39. Knudsen, T., (2006), Why We Need a Generalized Darwinism and Why Generalized Darwinism is not Enough, Journal of Economic Behavior and Organization, Volume 16, Number 1, PP: 1-19. doi:10.1016/j.jebo.2005.01.004.

40. Kortam, Wael. (2017), Non-linear marketing: A Universal philosophy of Marketing Thinking- Doing. : Perlen: Lambert academic publishing.

41. Kortam, Wael, Adaptability of Marketing Research To Service Industries: The Role of Encoding, Application and Decoding Phases in : Kortam, Wael and Mahrous, Abeer, (2010), Insights, Contexts, and Frontiers of Marketing Thought: An Advanced Book.

42. Kortam, Wael and Gad, Ghada, (2014), Generalized Darwinism For An Evolution Theory of Marketing Research: Survival For The Fittest of Marketing Knowledge, Proceedings of Marketing Research Summit, Marketing Edge, San Diego, California, USA, October.

43. Kortam, wael and Gad,Ghada,(2017), Using Marketing Panels As An Exploratory Empiricism For Substantiation of a Generalized Darwinism-Based Evolutionary Marketing Research, CUCBS,Cairo, Egypt.

44. Kortam, Wael, Mahrous, Abeer, and Attia, Samaa, (2012), Developing A Theory of Ubiquitous Marketing Research: Combining Ideology and Methodology of Marketing Research", Journal of American Science, Vol.8, Iss.4, pp 534. (ISSN: 1545-1003). http://www.americanscience.org.

45. Kortam, Wael, Adaptability of Marketing Research To Service Industries: The Role of Encoding, Application and Decoding Phases in : Kortam, Wael and Mahrous, Abeer, (2010), Insights, Contexts, and Frontiers of Marketing Thought: An Advanced

46. Laughton, J., (1997), Darwinism and The Behavioral Theory of Socio-Cultural Evolution: An Analysis, American Journal of Sociology, Volume 85, Number 2, PP:288 - 302.

47. Levit, GS, Hossfeld, U, Witt, U (2011) Can Darwinism Be 'Generalized' and of What Use Would This Be? J Evol Econ 21: 545-562, DOI: 10.1007/s00191-011-0235-3.

48. Lewontin, RC (1985) Adaptation. In: Levins, R, Lewontin, RC (eds) The Dialectical Biologist. Harvard University Press, Cambridge MA, pp. 65-84

49. Marion, J., (2006), Research Note: Marketing Ideology and Criticism - Legitimacy and Legitimization, Marketing Theory, Volume 6, Number 2, PP: 22-32. https://doi.org/10.1177/1470593106063985.

50. Marks, E., (2001), Information Darwinism chapter 6 : The Impact of the Internet on Global Manufacturing, Marketing, and Supply Chain Management Work, Google Books.

51. Matthews, R C O, (1984), Darwinism and Economic Change, Oxford University Economic Papers. IP: 41.34.213.242.

52. McCarthy, I.P. (2005). Toward a phylogenetic reconstruction of organizational life. Journal of Bioeconomics, 7 (3), pp. 271-307.

53. Mokyr, J. (2000). Evolutionary phenomena in technological change. In Ziman, J. (ed.), Technological Innovation as an Evolutionary Process. Cambridge: Cambridge University Press, pp. 52-65. ISBN:0-521-62361-8.

54. Mulcahy, K.V., (2003), Entrepreneurship or Cultural Darwinism? Privatization and American Culture Patronage, The Journal of Arts Management, Law and Society, Volume 33, Issue 3, PP: 165 - 184. https://doi.org/10.1080/10632920309597344

55. Murmann, JP (2003) Knowledge and Competitive Advantage: The Co-Evolution of Firms, Technology and National Institutions. Cambridge University Press, New York.

56. Nelson, RR (2006) Evolutionary Social Science and Universal Darwinism. J Evol Econ 16: 491-510, Last login jan,2019.

57. Nelson, RR, Winter, SG (1982), An Evolutionary Theory of Economic Change. Belknap Press, Cambridge MA.

58. Nooteboom, B. (2006). Organization, evolution, cognition and dynamic capabilities. Center Discussion Paper, No. 2006-41, pp. 1-23. http://dx.doi.org/10.2139/ssrn.962326 
Gad, G., \& Kortaam, W. (2020) Empirical Analysis of a Generalized Darwinism Triggered Theory of Evolutionary Marketing Research. Archives of Business Research, 8(5). 274-297.

59. Nunan, Daniel and Domenico Di, Marialaura.(2013), market research and the ethics of big data, international journal of market research, Vol 55, Issue 4. https://doi.org/10.2501/IJMR-2013-015

60. Pelikan, P (2011) Evolutionary developmental economics: how to generalize Darwinism fruitfully to help comprehend economic change. J Evol Econ 21: 341-366. DOI: 10.1007/s00191-010-0178-0.

61. Rosenwald, P.J. (2004), Accountable Marketing: The Economics of Data-driven Marketing, Thomson, New York, NY, pp. 239-58. ISBN-13: 978-0324203592.

62. Rubin, PH (2002) Darwinian Politics. New Brunswick: Rutgers University Press.

63. Saad, Gad and Gill, Tripat, (2000), Applications of Evolutionary Psychology in Marketing, Psychology and Marketing, Volume 17, Number 12, PP: 1005-1034.https://doi.org/10.1002/1520-6793(200012)17:12

64. Sammut-Bonnici, T., and Wensley, R., (2002), Darwinism, Probability and Complexity: Market-Based Organizational Transformation and Change Explained Through the Theories of Evolution, Industrial Journal of Management Reviews, Volume 4, Issue 3, PP: 291-315. https://doi.org/10.1111/1468-2370.00088.

65. Satter, B., (2009), Darwinism and a Strategy for Survival in Business, (London: Unicommoms Publishing Company).

66. Schriger, D.L., Altman, D.G., Vetter, J.A., Heafner, T. and Moher, D., 2010. Forest plots in reports of systematic reviews: a cross-sectional study reviewing current practice. International journal of epidemiology, 39(2), pp.421-429. doi: 10.1093/ije/dyp370.

67. Schubert, Christian, (2012), “Generalized Darwinism” and the Quest for an Evolutionary Theory of PolicyMaking. Max Planck Institute of Economics, Germany.

68. Schubert, Christian, (2012) Is Novelty Always a good Thing? Towards an Evolutionary Welfare Economics. J Evol Econ, forthcoming. DOI: 10.1007/s00191-011-0257-x.

69. Shadish, William R.; Cook, Thomas D.; Campbell, Donald T. (2002). Experimental and Quasi-Experimental Designs for Generalized Causal Inference (2nd ed.). Boston: Houghton Mifflin Company. p. 267.

70. Stoelhorst, C., (2009), The Naturalist View of Universal Darwinism: An Application to the Evolutionary Theory of the Firm, in: Hodgson, Geoffrey M., The Evolution of Economic Institutions: A Critical Reader, (Cheltenham, UK: The European Association for Evolutionary Political Economy and Edward Elgar Publishing Limited Company). ISBN 9781843766681.

71. Tadajewski, Mark. Chelekis, Jessica. DeBerry-Spence, Benet. Figueiredo, Bernardo. Kravets, Olga. Nuttavuthisit, Krittinee. Peñaloza, Lisa and Moisander, Johanna. (2015), the discourses of marketing and development: towards 'critical transformative marketing research'. Journal of Marketing Management. Vol. 30, Nos. 17-18, 1728-1771. https://doi.org/10.1080/0267257X.2014.952660

72. Vollmer, Christopher, (2010), Digital Darwinism in the New Marketing and Media Eco Systems, Google Books.

73. Vromen, Jack (2007) Generalized Darwinism in Evolutionary Economics: The Devil is in the Details. Papers on Economics and Evolution. Max Planck Institute of Economics, Jena, Germany. ISSN 1430-4716

74. Vromen, J (2008) Ontological issues in evolutionary economics: The Debate between Generalized Darwinism and the Continuity Hypothesis. Papers on Economics \& Evolution. Max Planck Institute of Economics, Jena Germany. http://hdl.handle.net/10419/31794.

75. Vromen, J (2010) Heterogeneous Economic Evolution: A Different View on Darwinizing Evolutionary Economics, Papers on Economics and Evolution. Max Planck Institute of Economics, Jena, Germany. ISSN 1430-4716

76. Whitman, DG (1998) Hayek contra pangloss on evolutionary systems. Constitutional Political Economy. 9:45-66. DOI: 10.1023/A:1009058615310.

77. Wilson, DS, Gowdy, J (2010) The Relevance of Evolutionary Science for Economic Theory and Policy. White Paper for NSF SBE Program Initiative "Framing Research for 2020 and Beyond.

78. Winter, S (1964) Economic Natural Selection and the Theory of the Firm. Yale Econ Essays 4: 225-272. 
79. Witt, U (2003), Economic Policy Making in Evolutionary Perspective. J Evol Econ 13:77-94. https://doi.org/10.4337/9781785365072.00022.

80. Witt, U. (2004), on the proper interpretation of 'evolution' in economics and its implications for production theory. Journal of Economic Methodology, 11, pp. 125-146. https://doi.org/10.1080/13501780410001694091

81. Wolsky, A., (2010), A Hundred Years of Darwinism, Journal of Biology and Thought, Volume 34, Issue 2, PP: 165 184. 